\title{
Uma proposta de construção geométrica usando a linguagem Logo
}

\author{
Maria Ivete Basniak \\ Professora, Universidade Estadual do Paraná (UNESPAR) \\ Campus de União da Vitória \\ basniak2000@yahoo.com.br
}

\begin{abstract}
Resumo
A proposta de atividade tem como objetivo motivar os alunos a aplicarem noções de matemática para a construção de um triângulo retângulo no computador, utilizando o software Super Logo. A atividade pode ser desenvolvida por alunos a partir do $9^{\circ}$ ano do Ensino Fundamental, pois envolve conteúdos de trigonometria, ângulos internos do triângulo, ângulos complementares e suplementares, Teorema de Pitágoras. Este artigo apresenta uma possibilidade de desenvolvimento da atividade, pois outras podem surgir quando os alunos se engajarem para resolvê-la.
\end{abstract}

Palavras-chave: Matemática. Ensino. Aprendizagem. Linguagem Logo. Triângulo Retângulo.

\section{A proposal for a geometric construction using the Logo language}

\begin{abstract}
The proposed activity aims to motivate students to apply math concepts to construct a triangle on the computer, using the software Super Logo. The activity may be applied for students from the $9^{\text {th }}$ grade of Elementary School, it involves contents of trigonometry, angles of the triangle, complementary and supplementary angles, Pythagorean Theorem. This article presents one possibility of development of activity because others may arise when students engage to solve it.
\end{abstract}

Keywords: Mathematics. Teaching. Learning. Language Logo. Right Triangle.

\section{Introdução}

A linguagem Logo integrou o topo das pesquisas na área de informática na década de 70, sendo que no final desta década e início da de 80, baseada nas teorias de Jean Piaget e em estudos de Papert, a UFRGS desenvolveu um trabalho com o Logo através do LEC/UFRGS (Laboratório de Estudos Cognitivos do Instituto de Psicologia da Universidade Federal do Rio Grande do Sul), a fim de compreender o raciocínio lógico-matemático de crianças buscando maneiras de intervenção na promoção da aprendizagem autônoma dessas.

Paralelo pesquisas realizadas no Rio Grande do Sul, em São Paulo, na UNICAMP, em 1973, "pesquisadores preocupados com as dificuldades da aprendizagem de Matemática 
apresentadas por crianças e adolescentes da escola pública", criaram neste Estado, o LEC. Desde então muitas atividades com a linguagem Logo foram propostas (VALENTE, 1999, p.19).

Nas últimas décadas a pesquisa e uso da linguagem Logo na educação foram deixados de lado, pois inúmeros softwares de matemática foram desenvolvidos, com os quais é possível realizar diversas atividades. Entretanto, apesar do tempo decorrido desde que o Logo passou a ser utilizado, ainda é possível propor atividades com o mesmo que despertem a curiosidade e criatividade e, que permitam utilizar conhecimentos matemáticos para resolvê-las.

\section{A proposta de atividade}

A atividade aqui proposta consiste na construção de um triângulo retângulo utilizando o software Super Logo através do modo direto, sendo posteriormente apresentado como pode ser feita a programação através do comando aprenda.

Para os que não conhecem e nunca tiveram contato com o Super Logo, o programa consiste basicamente de uma janela (Figura 1) em que são digitadas instruções que fazem com que uma "tartaruga" os execute desenhando na tela conforme os comandos forem dados.

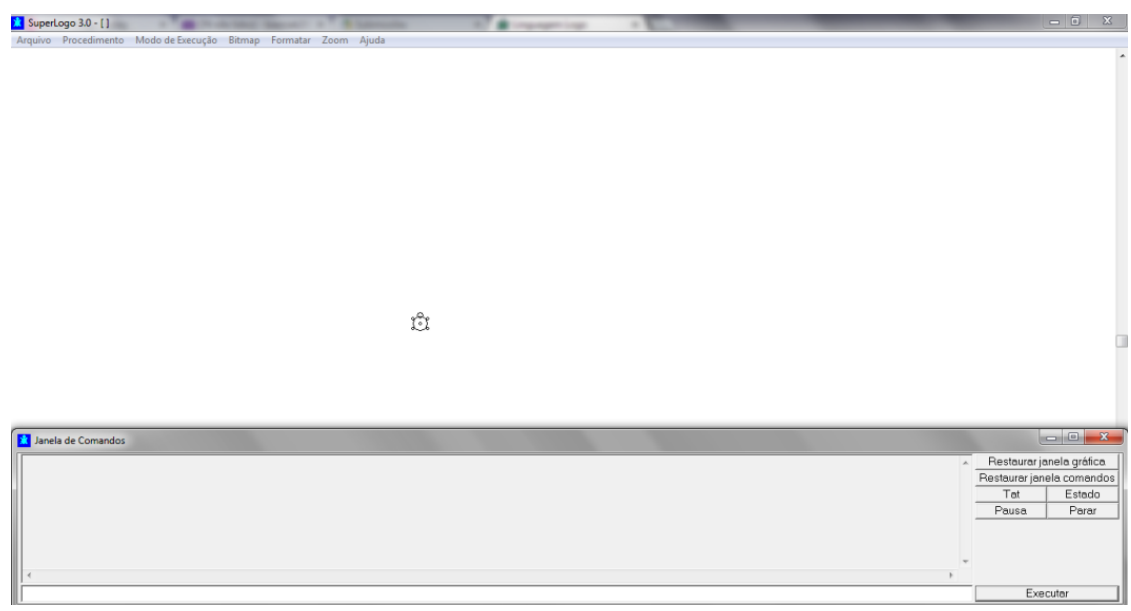

Figura1 - Tela inicial do Super Logo.

Fonte: A autora, 2014.

Para a realização da atividade proposta é suficiente conhecer os seguintes comandos:

- $p d \mathrm{n}^{\mathrm{o}}$. (para direita, valor referente a quantos graus a tartaruga deve girar), por exemplo, digitando o comando pd 90 - a tartaruga gira 90 graus à direita;

- pe $n^{\circ}$. (para esquerda, valor referente a quantos graus a tartaruga deve girar), por exemplo, digitando o comando pe 90 - a tartaruga gira 90 graus a esquerda;

- $p f n^{o}$. (para frente, valor referente a quanto a tartaruga deve andar), por exemplo, digitando o comando pd 90 - a tartaruga andará 90 passos para a frente; 
- $p t \mathrm{n}^{\mathrm{o}}$. (para trás, valor referente a quanto a tartaruga deve andar), por exemplo, digitando o comando pt 90 - a tartaruga andará 90 passos para trás.

Caso opte-se por deixar os alunos tentarem realizar a atividade primeiramente através de tentativa e erro, são necessários também os comandos:

- $\quad \mathrm{ul}$ - use lápis (a tartaruga deixa um rastro quando se movimenta);

- un - use nada (a tartaruga se movimenta sem deixar marcas);

- $\mathrm{ub}$ - use borracha (a tartaruga apaga traços deixados anteriormente).

Sabendo isso, o professor conduzirá a atividade que poderá ser realizada com alunos a partir do $9^{\circ}$ ano do Ensino Fundamental, com o objetivo de que usando diferentes conhecimentos matemáticos construam um triângulo retângulo no Super Logo. Inicialmente, pode-se lançar o desafio aos alunos de construírem um triângulo retângulo no Super Logo, podendo realizar a tarefa por tentativa e erro. Entretanto nesse caso, provavelmente precisarão utilizar a ferramenta borracha e ajustar o último lado e/ou ainda retornar ao primeiro lado desenhado do triângulo para apagar parte dele ou completá-lo, dependendo das medidas utilizadas nos lados e para girar a tartaruga. Pois sem utilizar determinados conhecimentos matemáticos é muito pequena a probabilidade de encontrar as medidas corretas para completar o último lado do triângulo sem precisar ajustá-lo. Aí cabe a primeira intervenção do professor em perguntar: "Seria possível desenhar esse triângulo sem ajustar o último lado? Como?”

A seguir apresentam-se os passos de uma forma como pode ser desenvolvida essa atividade, entretanto, é possível que os alunos encontrem ou sugiram outras possibilidades durante seu desenvolvimento.

Outras questões que podem ser feitas aos alunos: "É possível desenhar um triângulo retângulo com as medidas dos lados definidas? Podemos escolher aleatoriamente todas as medidas dos lados? Por quê?"

Pode-se trabalhar com o Teorema de Pitágoras para determinar as medidas dos lados do triângulo. O professor pode deixar livre que cada aluno determine as medidas de dois lados iniciais, ou pode discutir com os alunos as possibilidades para se chegar às medidas dos lados aproveitando para discutir as relações entre os catetos e a hipotenusa.

Definidos os lados do triângulo o professor pode questionar os alunos: "E agora, será que podemos girar a tartaruga com qualquer valor, se temos os valores das medidas dos lados do triângulo definidas e não queremos alterá-las?”

Embora existam várias formas de se iniciar o triângulo, uma sugestão é iniciar pelos catetos, cujo ângulo é fixo $\left(90^{\circ}\right)$ e por isso considera-se que, possivelmente, esta será a sugestão dos alunos. 


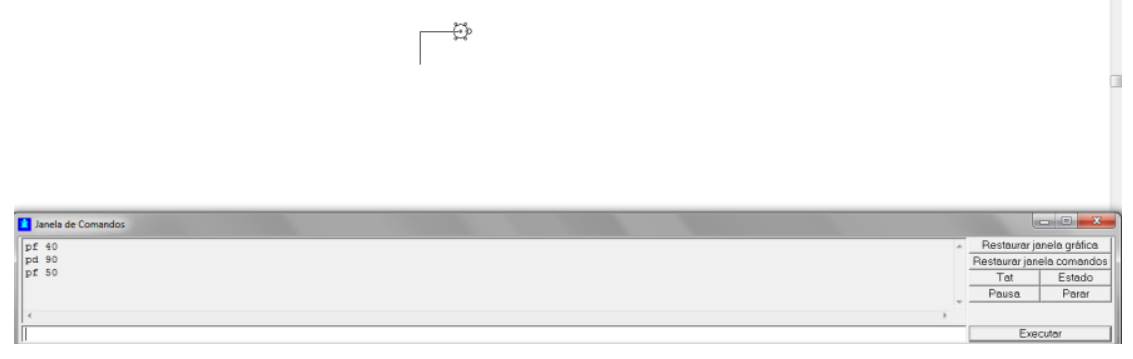

Figura 2 - Construção inicial.

Fonte: A autora, 2014.

Para finalizar a atividade com as medidas dos lados pré-fixadas, terão que girar a tartaruga corretamente para a direita. Uma das possibilidades, caso tenham sido construídos primeiramente os catetos, é trabalhar com a tangente, devendo dessa forma, encontrar o ângulo da tangente em questão. O software calcula a divisão (utilizando a barra para dividir dois valores) entre os catetos, que é o correspondente ao resultado do valor da tangente do ângulo alfa, do qual deve ser calculado o suplementar para encontrar o valor que a tartaruga deve girar.

Acredita-se que essa será a parte mais difícil de ser concluída pelos alunos, pois a primeira tentativa ao realizar a atividade, normalmente, surge ao se lembrar que a soma dos ângulos internos do triângulo é $180^{\circ}$ e dessa forma, intuitivamente considera-se que consegue-se "fechar" o triângulo, dividindo aleatoriamente $90^{\circ}$ entre os dois ângulos que restam.

É possível ainda mostrar aos alunos como "ensinar" a tartaruga a desenhar um triângulo retângulo através do comando aprenda. Por exemplo, para se ensinar a tartaruga a construir um triângulo retângulo com os lados 3, 4 e 5, basta digitar na entrada: aprenda trianguloretangulo (enter), ou o nome que os alunos preferirem. Uma caixa de diálogo se abrirá na qual pode ser dado os seguintes comandos:

aprenda trianguloretangulo

pf 30 pd 90 pf 40

pd 143 pf 50

fim

Posteriormente quando se desejar que a tartaruga desenhe um triângulo retângulo como o exposto na Figura 2, basta digitar na caixa de entrada: trianguloretangulo. 


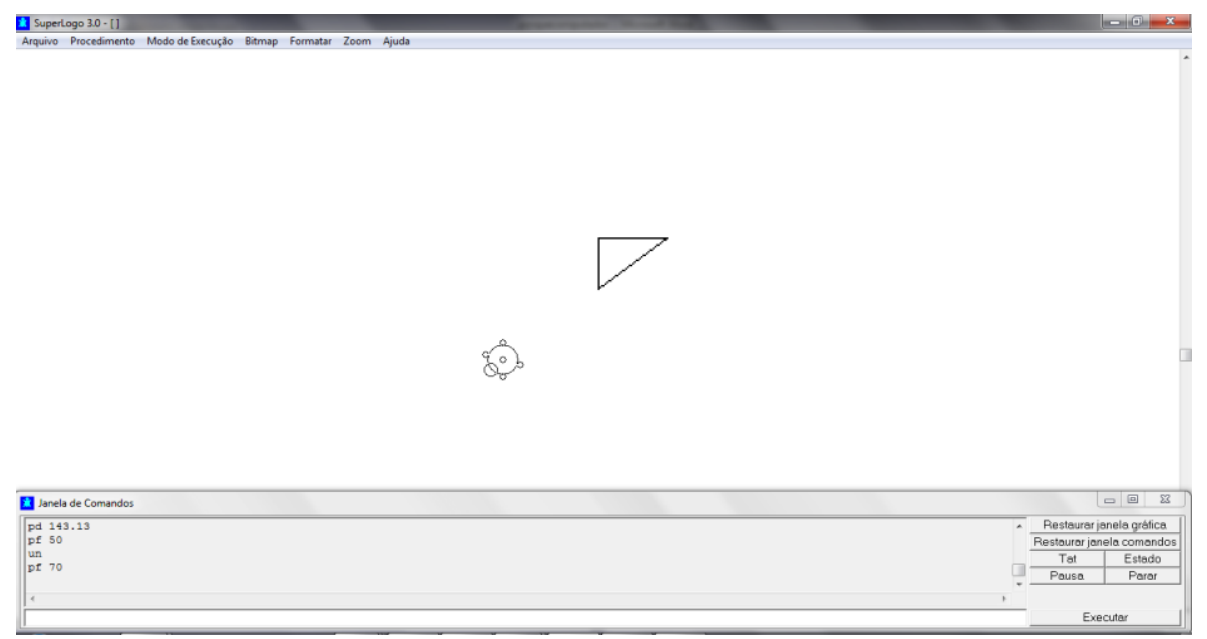

Figura 3 - Construção final.

Fonte: A autora, 2014.

\section{Considerações Finais}

A atividade proposta pode possibilitar a revisão de conteúdos anteriormente trabalhados, motivando os alunos a buscarem e testarem estratégias para conseguir resolver a questão. $\mathrm{Na}$ condução da atividade como descrita, considerou-se que o aluno já tenha estudado anteriormente os conteúdos envolvidos, mas dependendo da turma com que o professor pretende trabalhar pode ser usada para introduzir algum dos conteúdos citados no trabalho.

\section{Referências}

VALENTE, J. A. Informática na educação no Brasil: análise e contextualização histórica. In:

VALENTE, J. A. (Org.) O computador na sociedade do conhecimento. Coleção Informática para a mudança na sociedade. Brasília: MEC, 1999.

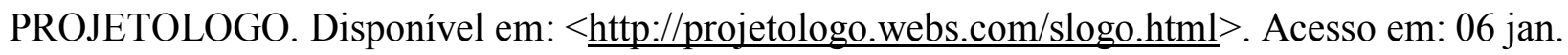
2014. 